\title{
A Twin Study of Nitric Oxide Levels Measured by Serum Nitrite/Nitrate
}

\author{
Lars Retterstol,' Torstein Lyberg, ${ }^{2}$ Trude Aspelin, ${ }^{2}$ and Kåre Berg \\ ' Department of Medical Genetics, Ullevål University Hospital, Oslo, Norway \\ ${ }^{2}$ Center for Clinical Research, Ullevål University Hospital, Oslo, Norway
}

$\mathrm{N}$ itrite and nitrate are the stable end products of the L-arginine-NO pathway, and the sum of nitrite and nitrate $\left(\mathrm{NO}_{x}\right)$ is a common way to measure nitric oxide (NO) production or secretion. To uncover any genetic influence on NO, we measured $\mathrm{NO}_{x}$ in serum samples from monozygotic twin pairs after an overnight fast. Heritability was estimated as intraclass correlation coefficient. We arrived at a heritability estimate of .32 (95\% confidence interval 0.17-0.45) for $\mathrm{NO}_{x}$. The numerical heritability estimate was higher for females than for males $(0.38$ vs. 0.21), and higher for nonsmokers than for smokers (0.36 vs. 0.22). The heritability estimate of $\mathrm{NO}_{x}$ was lower than the heritability estimate for other cardiovascular risk factors. This study suggests a low degree of heredity for $\mathrm{NO}_{\mathrm{x}}$ levels.

Nitric oxide (NO) is an exceptionally versatile molecule that influences diverse aspects of vascular biology in health and disease. NO is synthesized from L-arginine by a family of enzymes named nitric oxide synthases (NOS), and once formed NO can interact with a number of molecular targets with a variety of biological effects. The effect on the endothelium was first recognized. This molecule maintains a vasodilator tone that is essential for the regulation of blood flow and blood pressure after physical stimuli such as shear stress or chemical stimuli (Furchgott, 1990; Luscher, 1990; Moncada et al., 1989). Production of NO by the endothelial cells or platelets inhibits leukocyte adhesion as well as platelet aggregation and adhesion (Moncada \& Higgs, 1993). Thus, circulating $\mathrm{NO}$ has an important role in regulating vascular tonus and blood flow, and reduction in NO release may predispose to hypertension, thrombosis, vasospasm and atherosclerosis. NO has now made it from bench to bedside in cardiovascular medicine.

The most common way to measure NO is determining the sum of its plasma metabolites nitrite and nitrate $\left(\mathrm{NO}_{\mathrm{x}}\right)$. A significant genetic contribution to $\mathrm{NO}_{\mathrm{x}}$ level has been reported in a family study (Wang et al., 1997). The degree of genetic influence can be estimated as heritability, which reflects the genetic component of fenotypic variation between individuals. Twin studies are well suited for heritability calculations.
Cardiovascular disease itself and several of its risk factors exhibit a significant degree of heredity (Nora et al., 1991). In this study, we also provide a list of nine other established cardiovascular risk factors, and thus we are able to put the genetic contribution to $\mathrm{NO}_{\mathrm{x}}$ levels into a wider cardiovascular perspective. Thus, the purpose of this study was to estimate the heritability of $\mathrm{NO}_{x}$ and to compare it with that of other cardiovascular risk factors.

\section{$\overline{\text { Methods }}$ \\ Subjects}

Subjects were recruited from an extensive study of monozygotic (MZ) twins initiated in the late 1970s and the early 1980s. We have previously described the population-based Norwegian Twin Panel from which the twins were drawn (Berg, 1984). The present series of 155 pairs (68 male pairs and 87 female pairs) were between 38 and 57 years old (mean age 44 years). Blood pressure was measured after at least 5 minutes rest in the supine position (recorded as mean of three measurements). Height and weight had been measured and body mass index (BMI) had been calculated as weight (in kilograms) divided by the square of height (in meters). Smoking habits and other healthrelated variables had been extracted from a self-administered questionnaire.

\section{Laboratory Analyses}

All persons were bled in the morning in the fasting state. Serum samples were stored at $-70{ }^{\circ} \mathrm{C}$ until analyzed. Serum nitrate and nitrite $\left(\mathrm{NO}_{\mathrm{x}}\right)$, the stable end products of the L-arginine-NO pathway, were determined by a modification (Saetre et al., 2000) of the fluorimetric assay described by Misko et al. (1993). The sensitivity of this assay was $0.02 \mu \mathrm{M}$. The intraand interassay precision in our laboratory has previously been reported to be $4.4 \%$ and $12 \%$, respectively. The procedure was executed blindly at

Received 13 October, 2005; accepted 24 January, 2006.

Address for correspondence: Lars Retterstol, Ullevål University Hospital, Department of Medical Genetics, 0407 Oslo, Norway. E-mail:l.j.retterstol@medisin.uio.no 
the Center for Clinical Research, Ullevål University Hospital. $\mathrm{NO}_{\mathrm{x}}$ values are not available for all twins due to shortage of serum from some persons and this explains variation between variables with respect to number of persons examined.

Serum C-Reactive Protein (CRP) values were determined automatically using Dual-Radius Enhanced Latex technology at this hospitals Department of Clinical Chemistry (Eda et al., 1998).

Plasma total fibrinogen had been measured semiautomatically in the same department by the standard thrombin clotting time technique (Clauss, 1957).

Levels of plasma total homocysteine were determined by high-pressure liquid chromatography (HPLC) and electrochemical detection at Oregon Regional Primate Center, Beverton, Oregon (Berg et al., 1992).

Serum total cholesterol, high density lipoprotein cholesterol (HDL), and triglycerides were measured enzymatically and results recorded as $\mathrm{mmol} / \mathrm{L}$. The concentration of $L p(a)$ lipoprotein was determined by quantitative immunoelectrophoresis (Berg, 1984).

All analyses apart from $\mathrm{NO}_{x}$, CRP, fibrinogen and homocysteine determinations were conducted at the Institute of Medical Genetics, University of Oslo.

\section{Statistics}

The distribution of $\mathrm{NO}_{\mathrm{x}}$ was markedly skewed and we therefore applied nonparametric tests. MannWhitneys $U$ test was used to compare differences in $\mathrm{NO}_{x}$ levels according to dichotomous variables. Spearman's rho was used to uncover correlations of $\mathrm{NO}_{\mathrm{x}}$ values with other continuous variables and to check for within-pair correlations in MZ twins. The confidence interval of the correlation coefficient $r$ was based on the transformation $Z=1 / 2 \ln (1+r) /(1-r)$. Multiple regression analysis was applied to identify variables independently associated to $\mathrm{NO}_{x}$ (after ln transformation of $\mathrm{NO}_{\mathrm{x}}$ ).

All analyses were performed with the SPSS (SPSS Inc., 2003) statistical software.

Two-tailed $p$ values of less than .05 were considered statistically significant.

\section{Results}

Median levels of $\mathrm{NO}_{x}$ with 10th and 90th centiles for females and males are presented in Table 1. Females had slightly higher $\mathrm{NO}_{\mathrm{x}}$ levels than males, but the difference did not reach statistical significance $(p=.08)$. Smoking lowered $\mathrm{NO}_{x}$ levels (Table 2). The proportions of smokers were essentially the same in the two sexes $(41.5 \%$ for males and $42.5 \%$ for females). Daily alcohol intake appeared to lower $\mathrm{NO}_{\mathrm{x}}$ levels, but this effect did not reach statistical significance (Table 2).

Table 3 shows correlation coefficients between $\mathrm{NO}_{x}$ on one hand and several variables on the other hand, that is, HDL, triglycerides, CRP, BMI, plasminogen, $\mathrm{Lp}$ (a) lipoprotein, homocysteine and low density lipoprotein cholesterol (LDL). Age did not correlate to

\section{Table 1}

10th, 50th and 90th Centile of Serum NO Measured as the Sum of $\mathrm{NO}_{2}$ and $\mathrm{NO}_{3}{ }^{-}$in Members of Healthy Norwegian Twins $(n=287)$

\begin{tabular}{lcccc}
\hline Sex & $n$ & 10th centile & 50th centile & 90th centile \\
\hline Females & 163 & 29.0 & 39.0 & 55.5 \\
Males & 124 & 30.5 & 37.0 & 54.6 \\
All & 287 & 29.0 & 38.0 & 54.2 \\
\hline
\end{tabular}

$\mathrm{NO}_{\mathrm{x}}$. Only CRP $(p<.001)$ and HDL $(p=.01)$ were associated to $\ln \mathrm{NO}_{\mathrm{x}}$ in a multivariate model using linear regression analyses.

The heritability of $\mathrm{NO}_{x}$ was .32 . Table 4 shows the heritability of other cardiovascular risk factors measured in this study. We performed substudies of heritability according to gender and smoking habits. The numerical heritability estimate was higher for females than for males (.38 vs. .21), and lower for smokers than nonsmokers (.22 vs. .36), but these differences did not reach statistical significance.

\section{$\overline{\text { Discussion }}$}

Multiple roles of NO in physiology and pathophysiology have been revealed during the past decade. NO is associated not only with cardiovascular disease, but also with diseases of different other organ systems. Some of the diseases exhibit strong genetic predisposition. The degree of heredity for factors governing this molecule and its stable end products of the L-arginineNO pathway $\left(\mathrm{NO}_{\mathrm{x}}\right)$ is therefore of wide biological interest. Endothelium-dependent flow-mediated dilatation of the brachial artery (a NO-dependent response) is impaired in young healthy individuals with a firstdegree relative who has died of cardiovascular disease (Clarkson et al., 1997; Schachinger et al., 1999), indicating an inherited effect. Twin studies offer a more direct way to examine heritability. There are several ways to measure heritability, and in this twin study we calculated MZ intraclass correlation coefficients. This may overestimate heritability, as MZ twins not only share the same genes, but to a large extent also the same environments. This has nonetheless proved to be a practical and robust approach to determine heritability (Berg, 1993).

We found a heritability for $\mathrm{NO}_{x}$ of .32 , which is in line with a previous family study (Wang et al., 1997). As far as we are aware, this is the first twin study of

\section{Table 2}

Median Serum Levels of $\mathrm{NO}_{\mathrm{x}}$ (With Interquartile Range) Among Smokers $(n=115)$ and Those With a Daily Alcohol Consumption $(n=38)$

\begin{tabular}{lccc} 
Variable & Yes & No & $p$ value \\
\hline Smoking & $37.0(31.8,42.8)$ & $40.0(35.0,40.0)$ & .001 \\
Daily alcohol consumption & $40.0(34.0,46.3)$ & $37.0(32.0,43.0)$ & .12 \\
\hline
\end{tabular}




\section{Table 3}

Correlation Coefficients in Decreasing Order (Spearman's rho) Between $\mathrm{NO}_{\mathrm{x}}$ and Other Cardiovascular Risk Factors in Healthy Twins

\begin{tabular}{lcc}
\hline Variable & rho & $p$ value \\
\hline HDL-cholesterol & -.29 & $<.001$ \\
Triglycerides & .23 & $<.001$ \\
CRP & .22 & $<.001$ \\
BMI & .16 & .006 \\
Plasminogen & .16 & .006 \\
Homocysteine & .15 & .01 \\
Lp(a) lipoprotein & .15 & .01 \\
LDL cholesterol & .12 & .04 \\
Total cholesterol & .10 & .08 \\
Fibrinogen & .08 & .17 \\
Systolic BP & -.08 & .16 \\
Age & .008 & .89 \\
\hline
\end{tabular}

$\mathrm{NO}_{x}$ levels, and direct comparisons to other twin studies are not possible. A smaller study of Swedish and Finnish twins found a heritability of .24 for flowmediated vasodilatation of the brachial artery, also supporting a low genetic influence (Jartti et al., 2002). Comparisons to other biological variables can be helpful to point out which variables are (strongly) influenced by genes and which are not. As shown in Table 4, many other relevant variables in these MZ twins have a higher estimate of heritability than $\mathrm{NO}_{\mathrm{x}}$.

Genes encoding the enzymes producing NO (nitric oxide synthases [NOS]), such as endothelial NOS (eNOS), inducible NOS (iNOS) and neuronal NOS may all be of importance for $\mathrm{NO}_{x}$ levels. iNOS does not contribute to NO production under normal circumstances, but does so during pathological processes such as inflammation. eNOS appears to be especially

\section{Table 4}

Within-Pair Correlation Coefficients (With 95\% Confidence Intervals) in Decreasing Order in 155 Healthy MZ Twins for $\mathrm{NO}_{x}$ and Other Risk Factors of Cardiovascular Disease

\begin{tabular}{lc}
\hline Variable & Within-pair correlation \\
\hline Lp(a) lipoprotein & $\sim 1.0-$ \\
BMI & $.76(.68-.82)$ \\
Total cholesterol & $.68(.59-.76)$ \\
Systolic BP & $.64(.54-.72)$ \\
Homocysteine & $.53(.41-.63)$ \\
Diastolic BP & $.51(.38-.62)$ \\
Triglycerides & $.46(.33-.58)$ \\
CRP & $.40(.26-.52)$ \\
NO & $.32(.17-.45)$ \\
Fibrinogen & $.27(.12-.41)$ \\
\hline
\end{tabular}

Note: A heritability of 1 implies genetic determination exclusively. Other within-pair correlation coefficients are extracted from Berg (1993). important for $\mathrm{NO}_{x}$ levels in serum. This enzyme is continually expressed in the endothelium, and generates NO in response to shear stress and pulsative stretch. Several polymorphisms exist in the gene encoding this enzyme, and some of them have an effect on $\mathrm{NO}_{x}$ (Wang et al., 1997). In a recent metaanalysis it was concluded that some of these polymorphisms are associated with cardiovascular disease (Casas et al., 2004).

The numerical estimate of heritability was higher in nonsmokers than in smokers, although this difference did not reach statistical significance. This is not surprising, since smoking is an important environmental factor that influences $\mathrm{NO}_{x}$ levels. The reason for the gender difference in heritability of $\mathrm{NO}_{\mathrm{x}}$ observed in this study is obscure and should be addressed in future studies. Since the proportions of smokers were the same for both sexes, it cannot be explained by gender differences in smoking habits.

The short half-life of NO (seconds) makes direct determination of this molecule difficult (Moshage et al., 1995). Previous studies have shown that $\mathrm{NO}_{\mathrm{x}}$ levels in blood after an overnight fast reliably reflects endogenous NO production (Hibbs et al., 1992; Rosselli et al., 1995) but serum $\mathrm{NO}_{\mathrm{x}}$ levels may also reflect ingestion of nitrates/nitrites. Also, fluctuations under normal circumstances are likely to decrease estimates of heritability. In addition, our serum samples had been stored for several years before determination of $\mathrm{NO}_{\mathrm{x}}$. If $\mathrm{NO}_{\mathrm{x}}$ were unstable during long time storage, the precision of $\mathrm{NO}_{x}$ measurements would decrease. These factors could lead to underestimation of the degree of inheritance.

$\mathrm{NO}_{x}$ correlated significantly to several other variables. Several correlations to other established risk factors could indicate that these risk factors influence endothelial function through $\mathrm{NO}$ production and release. The strong correlation between $\mathrm{NO}_{x}$ and CRP, a marker of inflammation and a strong predictor of cardiovascular morbidity and mortality (Retterstol et al., 2002; Ridker et al., 1997) was of particular interest. In multivariate analyses only CRP and HDL were significantly associated with $\mathrm{NO}_{\mathrm{x}}$ levels. Association between HDL and improved endothelial function has been described previously (Watts et al., 1996). However, it is also possible that other risk factors affect the endothelium directly leading to changes in NO production and release, and that any change in $\mathrm{NO}_{x}$ levels is secondary to these effects.

$\mathrm{NO}_{x}$ levels were reduced in current smokers. This is in line with previous reports (Landmesser et al., 2004; Zeiher et al., 1995), indicating that the risk of smoking could be mediated through the endothelium. Interestingly, a study of a polymorphism in the eNOS gene and smoking (Wang et al., 1996) uncovered a gene-environment interaction affecting cardiovascular risk. Alcohol appeared to increase the levels of $\mathrm{NO}_{x}$, although this effect did not reach statistical significance. Alcohol affects endothelial function (Puddey et 
al., 2001) and the effect on NO production and release may contribute to the protective effect of alcohol on the cardiovascular system.

\section{Conclusions}

In this study of $\mathrm{MZ}$ twins, the within-pair correlation coefficient was .32 for $\mathrm{NO}_{x}$, the stable end-products of NO production and release, indicating only a moderate degree of heredity. Most other cardiovascular risk factors have a greater genetic component.

$\mathrm{NO}_{x}$ was significantly associated with other established cardiovascular risk factors.

\section{$\overline{\text { Acknowledgments }}$}

This study was supported by the Norwegian Council on Cardiovascular Diseases. We are grateful to R. Malinow, P. Kierulf and L. Eikvar for homocysteine, fibrinogen and CRP measurements, respectively.

\section{Reference List}

Berg, K. (1993). Genetic and environmental factors in the development of cardiovascular disease. In Biologie prospective (pp. 471-480). Paris: John Libbey.

Berg, K. (1984). Twin studies of coronary heart disease and its risk factors. Acta Geneticae Medicae et Gemellologiae, 33, 349-361.

Berg, K., Malinow, M. R., Kierulf, P., \& Upson, B. (1992). Population variation and genetics of plasma homocyst(e)ine level. Clinical Genetics, 41, 315-321.

Casas, J. P., Bautista, L. E., Humphries, S. E., \& Hingorani, A. D. (2004). Endothelial nitric oxide synthase genotype and ischemic heart disease: Meta-analysis of 26 studies involving 23028 subjects. Circulation, 109, 1359-1365.

Clarkson, P., Celermajer, D. S., Powe, A. J., Donald, A. E., Henry, R. M., \& Deanfield, J. E. (1997). Endothelium-dependent dilatation is impaired in young healthy subjects with a family history of premature coronary disease. Circulation, 96, 3378-3383.

Clauss, A. (1957). Gerinnungs-physiologische Schnellmethode zur Bestimmung des Fibrinogens [Rapid physiological coagulation method in determination of fibrinogen]. Acta Haematologica, 17, 237-246.

Eda, S., Kaufmann, J., Roos, W., \& Pohl, S. (1998). Development of a new microparticle-enhanced turbidimetric assay for C-reactive protein with superior features in analytical sensitivity and dynamic range. Journal of Clinical Laboratory Analysis, 12, 137-144.

Furchgott, R. F. (1990). The 1989 Ulf von Euler lecture. Studies on endothelium-dependent vasodilation and the endothelium-derived relaxing factor. Acta Physiologica Scandinavica, 139, 257-270.

Hibbs, J. B., Jr., Westenfelder, C., Taintor, R., Vavrin, Z., Kablitz, C., Baranowski, R. L., Ward, J. H., Menlove, R. L., McMurry, M. P., Kushner, J. P., \& Samlowski, W. E. (1992). Evidence for cytokine-inducible nitric oxide synthesis from L-arginine in patients receiving interleukin-2 therapy. Journal of Clinical Investigation, $89,867-877$.

Jartti, L., Ronnemaa, T., Kaprio, J., Jarvisalo, M. J., Toikka, J. O., Marniemi, J., Hammar, N., Alfredsson, L., Saraste, M., Hartiala, J., Koskenvuo, M., \& Raitakari, O. T. (2002). Population-based twin study of the effects of migration from Finland to Sweden on endothelial function and intima-media thickness. Arteriosclerosis, Thrombosis, and Vascular Biology, 22, 832-837.

Landmesser, U., Hornig, B., \& Drexler, H. (2004). Endothelial function: A critical determinant in atherosclerosis? Circulation, 109, II27-II33.

Luscher, T. F. (1990). Endothelium-derived vasoactive factors and regulation of vascular tone in human blood vessels. Lung, 168(Suppl.), 27-34.

Misko, T. P., Schilling, R. J., Salvemini, D., Moore, W. M., \& Currie, M. G. (1993). A fluorometric assay for the measurement of nitrite in biological samples. Analytical Biochemistry, 214, 11-16.

Moncada, S., \& Higgs, A. (1993). The L-arginine-nitric oxide pathway. The New England Journal of Medicine, 329, 2002-2012.

Moncada, S., Palmer, R. M., \& Higgs, E. A. (1989). The biological significance of nitric oxide formation from L-arginine. Biochemical Society Transactions, 17, 642-644.

Moshage, H., Kok, B., Huizenga, J. R., \& Jansen, P. L. (1995). Nitrite and nitrate determinations in plasma: A critical evaluation. Clinical Chemistry, 41, 892-896.

Nora, J., Berg, K., \& Nora, A. H. (1991). Atherosclerosis and coronary artery disease. In Cardiovascular diseases. Genetics, epidemiology and prevention (pp. 3-40). New York: Oxford University Press.

Puddey, I. B., Zilkens, R. R., Croft, K. D., \& Beilin, L. J. (2001). Alcohol and endothelial function: A brief review. Clinical and Experimental Pharmacology \& Physiology, 28, 1020-1024.

Retterstol, L., Eikvar, L., Bohn, M., Bakken, A., Erikssen, J., \& Berg, K. (2002). C-reactive protein predicts death in patients with previous premature myocardial infarction: A 10 year follow-up study. Atherosclerosis, 160, 433-440.

Ridker, P. M., Cushman, M., Stampfer, M. J., Tracy, R. P., \& Hennekens, C. H. (1997). Inflammation, aspirin, and the risk of cardiovascular disease in apparently healthy men. The New England Journal of Medicine, 336, 973-979.

Rosselli, M., Imthurn, B., Keller, P. J., Jackson, E. K., \& Dubey, R. K. (1995). Circulating nitric oxide (nitrite/nitrate) levels in postmenopausal women substituted with 17 beta-estradiol and norethisterone acetate. A two-year follow-up study. Hypertension, $25,848-853$.

Saetre, T., Hoiby, E. A., Aspelin, T., Lermark, G., Egeland, T., \& Lyberg, T. (2000). Aminoethylisothiourea, a nitric oxide synthase inhibitor and 
oxygen radical scavenger, improves survival and counteracts hemodynamic deterioration in a porcine model of streptococcal shock. Critical Care Medicine, 28, 2697-2706.

Schachinger, V., Britten, M. B., Elsner, M., Walter, D. H., Scharrer, I., \& Zeiher, A. M. (1999). A positive family history of premature coronary artery disease is associated with impaired endothelium-dependent coronary blood flow regulation. Circulation, 100, 1502-1508.

SPSS Inc. (2003). SPSS for Windows (Release 12.0) [Computer software]. Chicago, IL: SPSS, Inc.

Wang, X. L., Mahaney, M. C., Sim, A. S., Wang, J., Wang, J., Blangero, J., Almasy, L., Badenhop, R. B., \& Wilcken, D. E. (1997). Genetic contribution of the endothelial constitutive nitric oxide synthase gene to plasma nitric oxide levels. Arteriosclerosis, Thrombosis, and Vascular Biology, 17, 3147-3153.
Wang, X. L., Sim, A. S., Badenhop, R. F., McCredie, R. M., \& Wilcken, D. E. (1996). A smoking-dependent risk of coronary artery disease associated with a polymorphism of the endothelial nitric oxide synthase gene. Nature Medicine, 2, 41-45.

Watts, G. F., O’Brien, S. F., Silvester, W., \& Millar, J. A. (1996). Impaired endothelium-dependent and independent dilatation of forearm resistance arteries in men with diet-treated non-insulin-dependent diabetes: Role of dyslipidaemia. Clinical Science (London), 91, 567-573.

Zeiher, A. M., Schachinger, V., \& Minners, J. (1995). Long-term cigarette smoking impairs endotheliumdependent coronary arterial vasodilator function. Circulation, 92, 1094-1100. 